\title{
Erratum to: The impact of a two- versus three-yearly cervical screening interval recommendation on cervical cancer incidence and mortality: an analysis of trends in Australia, New Zealand, and England
}

\author{
Leonardo Simonella $\cdot$ Karen Canfell
}

Published online: 31 August 2013

(C) Springer Science+Business Media Dordrecht 2013

Erratum to: Cancer Causes Control (2013) 24:1727-1736

DOI 10.1007/s10552-013-0250-9

Unfortunately, the original publication of the article included error in the first sentence of the "Background" section. The corrected sentence should read "Organized screening was rolled out in England in 1988 and in Australia and in New Zealand in 1991.”

The online version of the original article can be found under doi:10.1007/s10552-013-0250-9.

L. Simonella $(\bowtie) \cdot$ K. Canfell

Cancer Epidemiology Research Unit, Cancer Council NSW, 153

Dowling Street, Woolloomooloo, Sydney, NSW 2011, Australia

e-mail: leosimonella@gmail.com

K. Canfell

e-mail: k.canfell@unsw.edu.au

L. Simonella $\cdot$ K. Canfell

School of Public Health, Sydney Medical School, University of

Sydney, Sydney, Australia

Present Address:

L. Simonella

Saw Swee Hock School of Public Health, National University of

Singapore, 16 Medical Drive, Block MD3,

Singapore 117597, Singapore

Present Address:

K. Canfell

Lowy Cancer Research Centre, Prince of Wales Clinical School,

University of NSW, Sydney, Australia 